\title{
Cement - Steatite Composites Reinforced with Carbon Fibres: an Alternative for Restoration of Brazilian Historical Buildings
}

\author{
Túlio Hallak Panzera ${ }^{\mathrm{a} *}$, Kurt Strecker ${ }^{\mathrm{a}}$, Jader dos Santos Miranda ${ }^{\mathrm{a}}$, \\ André Luis Christoforo ${ }^{\mathrm{a}}$, Paulo Henrique Ribeiro Borges ${ }^{\mathrm{b}}$ \\ ${ }^{a}$ Department of Mechanical Engineering, \\ Federal University of São João del Rei - UFSJ, Brazil \\ ${ }^{\mathrm{b}}$ Department of Civil Engineering, \\ Federal Centre for Technological Education of Minas Gerais - CEFET-MG, Brazil
}

Received: December 16, 2010; Revised: February 2, 2011

\begin{abstract}
Steatite is a mineral which has been employed in the carving of elements in facades of Brazilian historical buildings and churches since the $17^{\text {th }}$ century. Over the years, many of those historical buildings suffered the consequences of weathering with a current need for restoration. Recently a special cement-based mortar containing additions of fine powder waste from mineral extraction of steatite has been developed in Brazil, as a composite material for restoration of steatite elements. However, the incorporation of steatite waste reduces the flexural strength of the mortar and compromises the restoration of elements where gravity imposes tensile stresses. The addition of carbon fibres may overcome this issue and increase the flexural strength of the cement-steatite composite mortar. This work investigates the effect of carbon fibre addition on the bulk density and flexural strength of compacted precast cement-steatite composites. The results show that the addition of carbon fibres (i) effectively increases the mechanical strength, allowing for a higher amount of steatite powder waste in the mixes; (ii) reduces the weight of the structural elements. This new composite material would help to develop restoration techniques of historical buildings and serve as a disposal route of steatite powder waste in Brazil.
\end{abstract}

Keywords: steatite, carbon fibres, cementitious composites, full factorial design

\section{Introduction}

The mineral steatite, commonly known as soapstone, is a metamorphic rock composed mainly of talc $\left(\mathrm{Mg}_{3} \mathrm{Si}_{4} \mathrm{O}_{10}(\mathrm{OH})_{2}\right)$ and many other minerals such as magnesite and silica ${ }^{1,2}$. Steatite has been widely employed in the carving of elements in facades of Brazilian historical buildings and baroque churches since the $17^{\text {th }}$ century. Those buildings are now part of the world heritage ${ }^{3}$.

Over the years, many of those historical buildings suffered the consequences of weathering with a current need for restoration or complete replacement of some steatite elements. In addition, other wear mechanisms take place on the stone surface such as degradation and deterioration which are related not only to natural factors, but also human actions ${ }^{3}$. The degradation is an alteration of the material surface that always assumes degeneration of its characteristics according to a conservative perspective. On the other hand, deterioration affects directly the carved rock located in the facades of buildings ${ }^{4}$.

However, the lack of expertise on restoration of soapstone craftwork elements brings on polemic discussions. Cement mortars are the most common materials used to restore the macrocracks and rebuild missing parts of soapstone craftwork in Brazil. The physical characteristics of cementitious materials are such that provides (i) imperfect adhesion to the soapstone elements; (ii) texture and colour different from the natural stone, which is obviously undesired. Strecker et al. ${ }^{5}$ investigated a special cement-based mortar containing additions of fine steatite powder waste from mineral extraction in an attempt of producing a strong and durable restoration material with similar characteristics of the natural stone. However, the incorporation of steatite waste to those new composites reduces the flexural strength of the mortar and compromises the restoration of elements where gravity imposes tensile stresses. Therefore, the addition of unidirectional carbon fibres into the steatite cementitious composites has been proposed to increase the flexural strength and the stiffness of this material, making it more reliable for restoration purposes. Three point bending tests were carried out to characterize the mechanical properties of the composites, which might be used in the future to perform a structural analysis and precisely design the restored elements for any specific application.

\section{Materials and Methods}

\subsection{Matrix phase: Portland cement}

The physical and chemical analysis of the Portland cement (CP-V ARI PLUS), shown in Table 1, are in accordance with the Brazilian Standard requirements (NBR 11578-ABNT) ${ }^{6}$.

\subsection{Dispersive phases: steatite mineral and carbon fibres}

The steatite waste was received from the city of Congonhas, state of Minas Gerais, Brazil. The particles were dried at $80{ }^{\circ} \mathrm{C}$ for 24 hours and later on classified by sieving within two particle size ranges: $1.19 / 0.42$ and $0.149 / 0.074 \mathrm{~mm}$. Table 2 shows the chemical analysis of the steatite, carried out by X-ray fluorescence spectroscopy, showing high percentages of silicon oxide $(44.73 \%)$ and magnesium oxide (29.28\%).

The unidirectional carbon fibres with $360 \mathrm{~g} \cdot \mathrm{m}^{-2}$ of fabric were supplied by All Tech Company (Brazil). The carbon fibres were cut and assembled in two parallel strips of $5 \mathrm{~mm}$ width (Figure 1), which were longitudinally positioned into the samples. 
Table 1. Physical and chemical analysis of the Portland cement.

\begin{tabular}{cc}
\hline Chemical compound & Results $(\%)$ \\
\hline $\mathrm{SiO}_{2}$ & 19.45 \\
$\mathrm{CaO}$ & 64.14 \\
$\mathrm{Al}_{2} \mathrm{O}_{3}$ & 4.75 \\
$\mathrm{Fe}_{2} \mathrm{O}_{3}$ & 3.12 \\
$\mathrm{SO}_{3}$ & 2.85 \\
$\mathrm{CO}_{2}$ & 1.13 \\
$\mathrm{MgO}$ & 0.80 \\
$\mathrm{~K}_{2} \mathrm{O}$ & 0.66 \\
$\mathrm{Na}_{2} \mathrm{O}$ & 0.21 \\
Air permeability (Blaine) $\left(\mathrm{cm}^{2} \cdot \mathrm{g}^{-1}\right)$ & 4729 \\
\hline
\end{tabular}

Table 2. Chemical analysis of steatite mineral.

\begin{tabular}{cc}
\hline Chemical compound & Results (\%) \\
\hline $\mathrm{SiO}_{2}$ & 44.73 \\
$\mathrm{Al}_{2} \mathrm{O}_{3}$ & 3.70 \\
$\mathrm{Fe}_{2} \mathrm{O}_{3}$ & 8.38 \\
$\mathrm{TiO}_{2}$ & $<0.001$ \\
$\mathrm{CaO}$ & 2.95 \\
$\mathrm{MgO}$ & 29.28 \\
$\mathrm{NaO}_{2}$ & $<0.001$ \\
$\mathrm{KO}_{2}$ & $<0.001$ \\
$\mathrm{MnO}_{2}$ & 0.13 \\
$\mathrm{P}_{2} \mathrm{O}_{5}$ & 0.01 \\
Loss of ignition & 10.34 \\
\hline
\end{tabular}

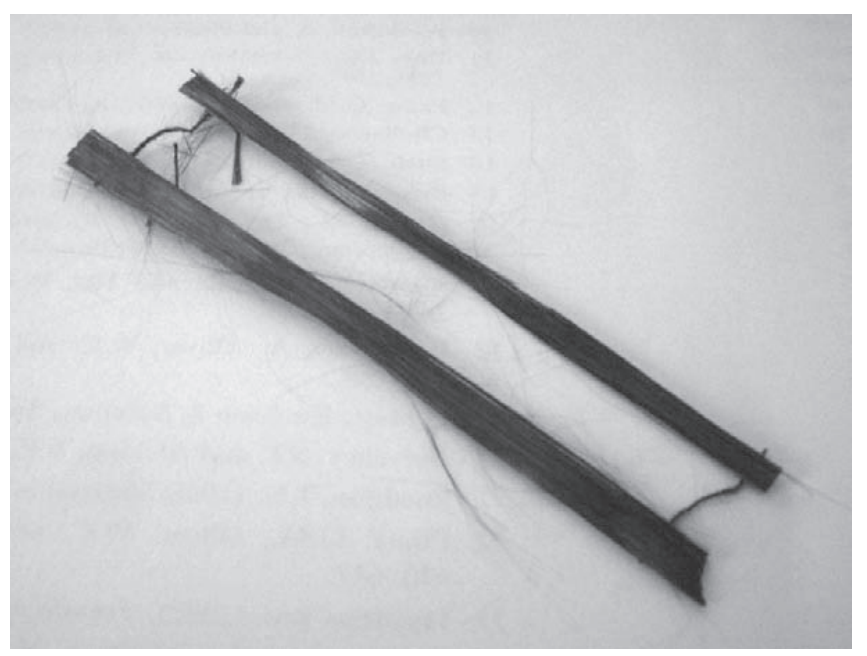

Figure 1. Carbon fibre assembles.

\subsection{Full factorial design}

The full factorial design of the type $\mathrm{n}^{\mathrm{k}}$ consists of investigating all the possible combinations of the experimental factors $(\mathrm{k})$ and its respective levels (n). The result of the factorial $n^{k}$ corresponds to the number of the investigated experimental conditions $\mathrm{s}^{7,8}$.

The following responses of the physical properties were investigated in this experiment: bulk density and flexural strength. Bulk density is defined as the weight per unit volume of material.
Table 3. Experimental planning matrix.

\begin{tabular}{|c|c|c|c|c|}
\hline & $\begin{array}{l}\text { Particle size } \\
\text { range } \\
(\mathrm{mm})\end{array}$ & $\begin{array}{l}\text { Steatite } \\
\text { fraction } \\
(\%)\end{array}$ & $\begin{array}{c}\text { Compacting } \\
\text { pressure } \\
(\mathrm{MPa})\end{array}$ & $\begin{array}{c}\text { Carbon fibre } \\
\text { addition } \\
(\mathrm{CF})\end{array}$ \\
\hline $\mathrm{C} 1$ & $1.19-0.42$ & 5 & 10 & - \\
\hline $\mathrm{C} 2$ & $1.19-0.42$ & 5 & 10 & $\mathrm{CF}$ \\
\hline $\mathrm{C} 3$ & $1.19-0.42$ & 5 & 30 & - \\
\hline $\mathrm{C} 4$ & $1.19-0.42$ & 5 & 30 & $\mathrm{CF}$ \\
\hline C5 & $1.19-0.42$ & 20 & 10 & - \\
\hline C6 & $1.19-0.42$ & 20 & 10 & $\mathrm{CF}$ \\
\hline $\mathrm{C} 7$ & $1.19-0.42$ & 20 & 30 & - \\
\hline $\mathrm{C} 8$ & $1.19-0.42$ & 20 & 30 & $\mathrm{CF}$ \\
\hline C9 & $1.19-0.42$ & 40 & 10 & - \\
\hline $\mathrm{C} 10$ & $1.19-0.42$ & 40 & 10 & $\mathrm{CF}$ \\
\hline $\mathrm{C} 11$ & $1.19-0.42$ & 40 & 30 & - \\
\hline $\mathrm{C} 12$ & $1.19-0.42$ & 40 & 30 & $\mathrm{CF}$ \\
\hline C13 & $0.149-0.074$ & 5 & 10 & - \\
\hline C14 & $0.149-0.074$ & 5 & 10 & $\mathrm{CF}$ \\
\hline C15 & $0.149-0.074$ & 5 & 30 & - \\
\hline $\mathrm{C} 16$ & $0.149-0.074$ & 5 & 30 & $\mathrm{CF}$ \\
\hline $\mathrm{C} 17$ & $0.149-0.074$ & 20 & 10 & - \\
\hline C18 & $0.149-0.074$ & 20 & 10 & $\mathrm{CF}$ \\
\hline C19 & $0.149-0.074$ & 20 & 30 & - \\
\hline $\mathrm{C} 20$ & $0.149-0.074$ & 20 & 30 & $\mathrm{CF}$ \\
\hline $\mathrm{C} 21$ & $0.149-0.074$ & 40 & 10 & - \\
\hline $\mathrm{C} 22$ & $0.149-0.074$ & 40 & 10 & $\mathrm{CF}$ \\
\hline $\mathrm{C} 23$ & $0.149-0.074$ & 40 & 30 & - \\
\hline $\mathrm{C} 24$ & $0.149-0.074$ & 40 & 30 & $\mathrm{CF}$ \\
\hline
\end{tabular}

The samples were oven dried and weighted and the volume was determined measuring the geometric parameters of the prismatic sample used in flexural testing. The three bending testing was conducted based on the recommendations of British Standard (BS EN 658) $)^{9}$. The flexural strength was calculated using the following expressions:

$$
\sigma=\frac{3 F L}{2 b h^{2}}
$$

where:

- $\sigma$ is the flexural strength (MPa);

- $F$ is the maximum flexural force $(\mathrm{N})$ after test specimen failure;

- $L$ is the outer span (mm);

- $b$ is the mean width of the test specimen (mm); and

- $h$ is the mean thickness of the test specimen (mm).

Four experimental factors were chosen: fraction of the dispersive phase of steatite $(5,20$ and 40\%), particle size range (1.19/0.42 and $0.149 / 0.074 \mathrm{~mm}$ ), compaction pressure (10 and $30 \mathrm{MPa}$ ) and carbon fibre addition. The constant factors constant in the experiment were: type of matrix (Portland cement); water to cement ratio (0.3); time of mixture (5 minutes) and temperature of manufacture $\left(22{ }^{\circ} \mathrm{C}\right)$. Table 3 shows the experimental factors and the levels investigated in this work, establishing a factorial planning of type $3^{1} 2^{3}$, supplying 24 distinct experimental combinations.

The statistical method of Design of Experiment (DOE) and the Analysis of Variance (ANOVA) provided the significance of each experimental factor on the responses. The statistical software Minitab version 14 was used for the treatment of the data and analysis of the results. 


\subsection{Specimen manufacturing}

The manufacture and curing of the composites followed the recommendations of the British Standard EN12390-2 ${ }^{[10]}$, in order to allow only a small variability in the manufacturing process. The randomization procedure was also adopted to manufacture the test samples, so that non-controlled factors did not affect the responses ${ }^{7,8}$.

A prismatic steel mould was used to compact the samples, with dimensions $20.5 \times 70.6 \times 8.5 \mathrm{~mm}$ according to the recommendations of British Standard (BS EN 658) ${ }^{9}$. Each fresh composite was poured and compacted under two pressure levels, i.e. 10 and $30 \mathrm{MPa}$, for 30 seconds. Afterwards, the samples were packed in plastic bags to avoid any loss of moisture during curing. The compaction was carried out in two steps in order to locate the carbon fibres assemble halfway the thickness of the sample. Figure 2a shows the sample after curing and Figure $2 b$ shows the fracture surface image obtained by backscattering electron image on SEM, exhibiting the carbon fibre embedded in the cementitious matrix.

Six test samples were manufactured for each experimental condition. Two replicates and 24 experimental conditions provided 288 samples. The replicate consists of the repetition of the experimental condition, in order to provide an estimation of the magnitude of the experimental error against which the differences among treatments are judged. The extension of this error is important to decide whether significant effects exist or if they may be attributed to the action of the factors ${ }^{7,8}$.

\section{Results}

Table 4 exhibits the P-values of Analysis of Variance (ANOVA) for the mean of the responses and the investigated factors: steatite particle size range $(\mathrm{P})$, steatite fraction $(\mathrm{F})$, compacting pressure $(\mathrm{C})$ and carbon fibre addition (A). The P-values (Table 4) indicate which of the effects in the system are statistically significant, based on examination of the experimental data from replicate 1 and replicate 2. If the P-value is less than or equal to 0.05 the effect is considered significant. An $\alpha$-level of 0.05 is the level of significance which implies that with $95 \%$ probability the effect is significant. The results will be presented via 'main effect' and 'interaction' plots. These graphic plots cannot be considered typical 'scatter' plots, but serve to illustrate the statistical analysis and provide the variation on the significant effects. The main effect of a factor must be interpreted individually only if there is no evidence that one factor does not interact with others. When one or more interaction effects of superior order are significant, the factors that interact must be considered jointly ${ }^{7,8}$.

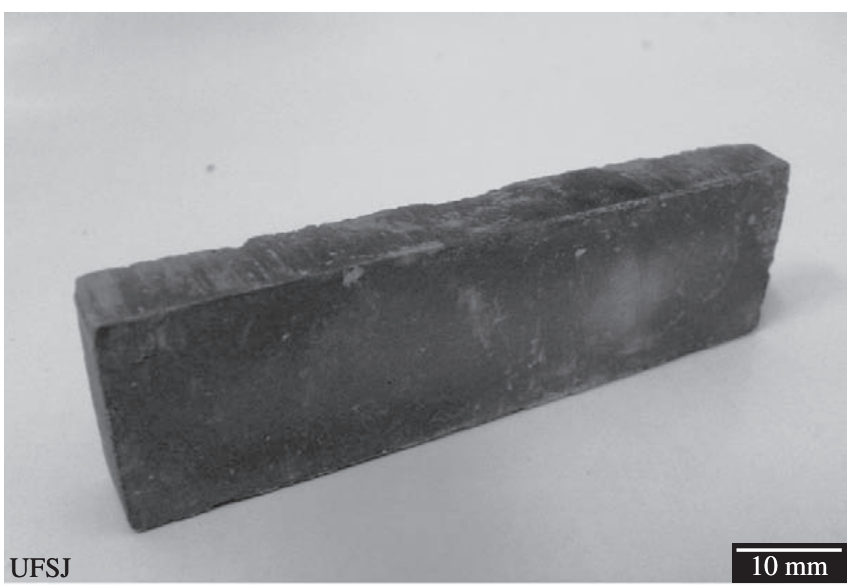

(a)
The value of ' $\mathrm{R}^{2}$ adjust' shown in the ANOVA analysis indicates how well the model predicts responses for new observations. Larger values of adjusted $R^{2}$ (adj) suggest models of greater predictive ability ${ }^{7,8}$. Table 4 shows the values of $R^{2}$ (adj) for the responses observing a variation from 82.39 to $98.16 \%$ showing that the quality of adjustment of the models was satisfactory.

The normal probability plot indicates whether the data are normally distributed, other variables are influencing the response, or outliers exist in the data. The normal probability plots shown in Figure 3 reveal that the bulk density (Figure 3a) and flexural strength (Figure $3 b$ ) data are in accordance to the conditions of normality for validation of the ANOVA analysis.

\subsection{Bulk density}

The bulk density data varied from 1.93 to $2.30 \mathrm{~g} . \mathrm{cm}^{-3}$. The P-values $(0.004 ; 0.002$ and 0.000$)$ underlined in Table 4 show that the main effect fraction of steatite $(\mathrm{F})$ and the interactions of particle size range and carbon fibre addition $\left(\mathrm{P}^{*} \mathrm{~A}\right)$ and compaction and carbon fibre addition $\left(C^{*} A\right)$ are significant. Figure 4 shows the effect of the

Table 4. Analysis of Variance (P-values).

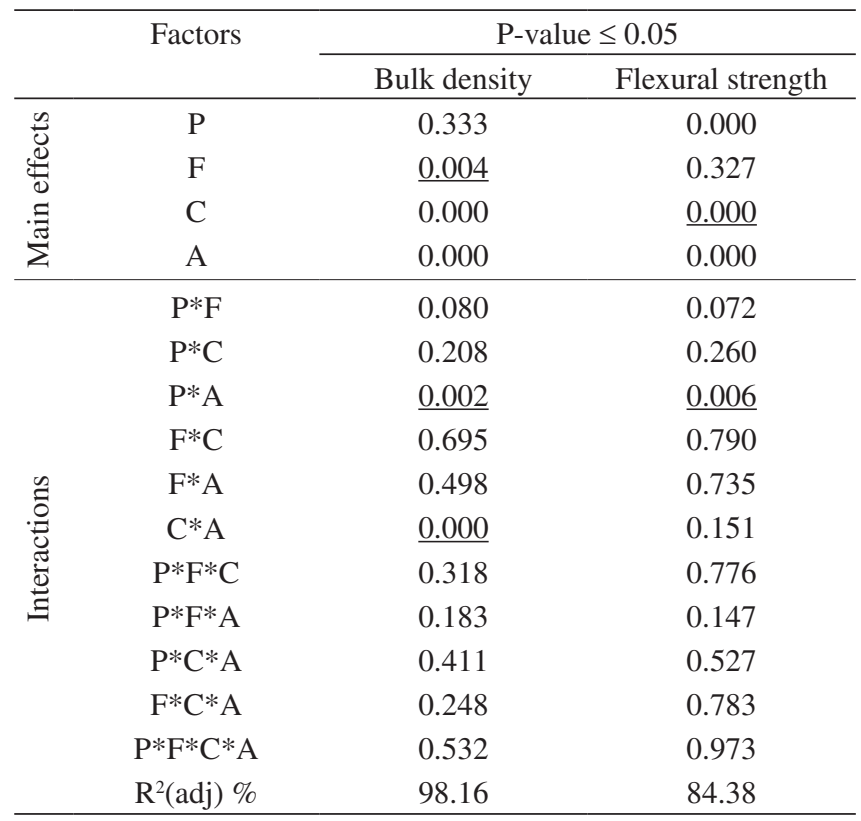

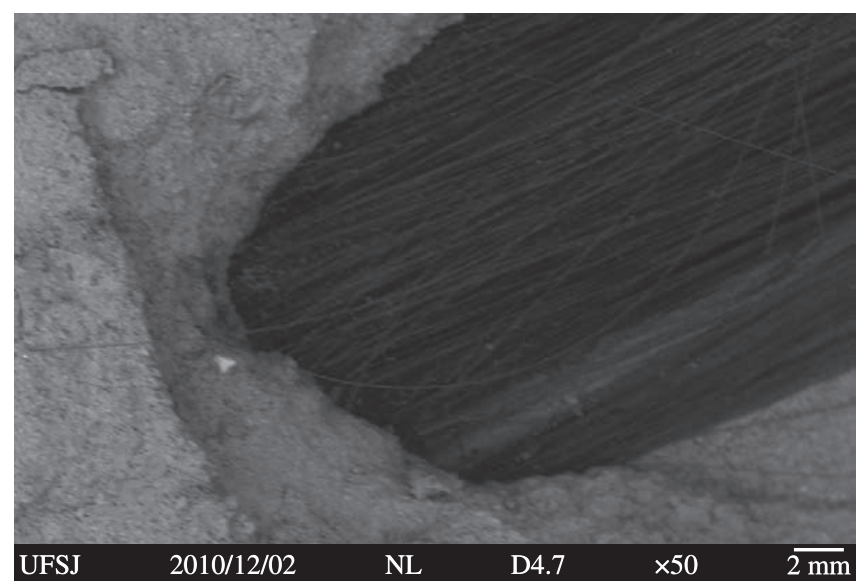

(b)

Figure 2. Prismatic sample (optical image) (a) and fracture surface (SEM) (b). 


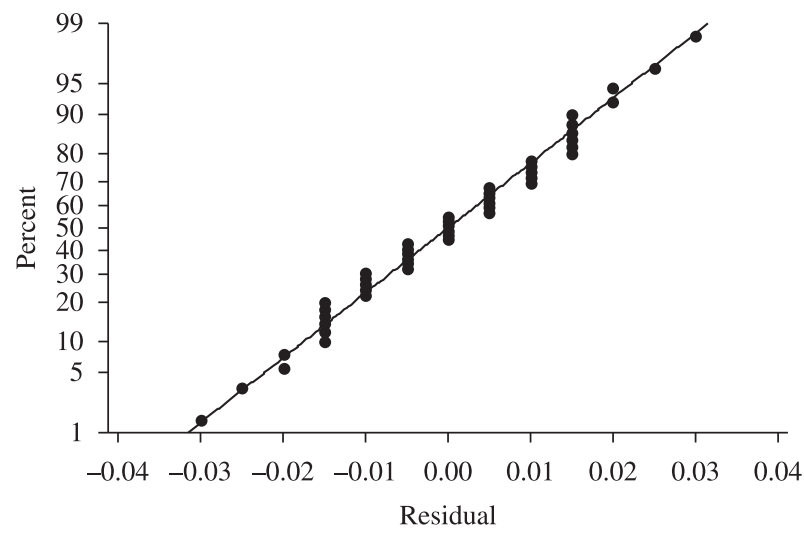

(a)

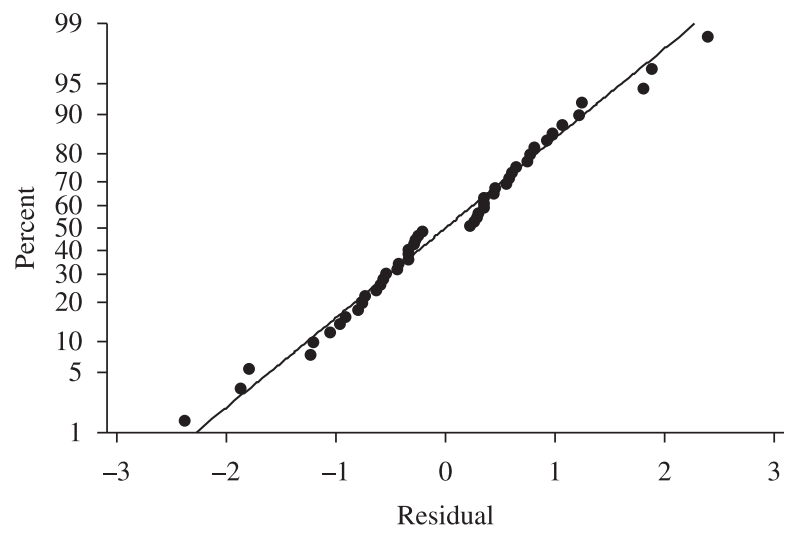

(b)

Figure 3. Normal probability plot for the bulk density (a) and flexural strength (b) responses.

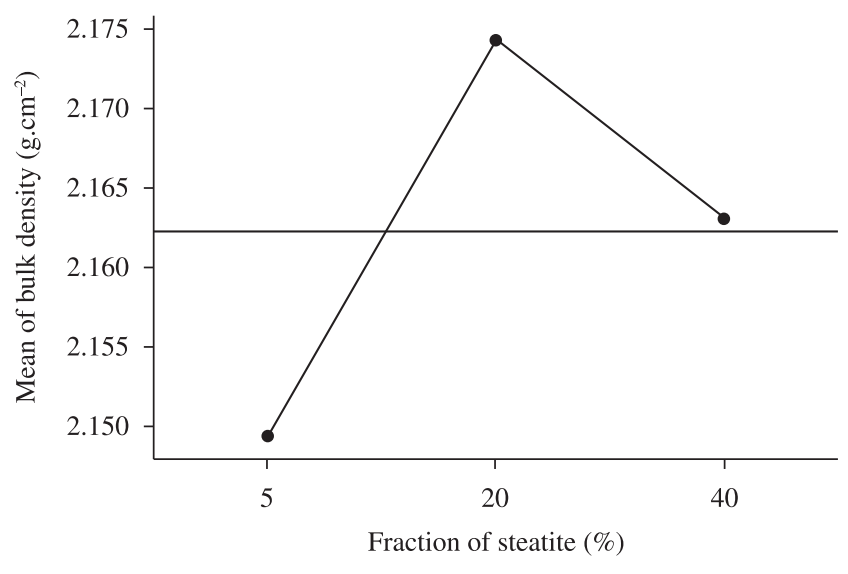

Figure 4. Main effect of steatite fraction on the bulk density of the composites.

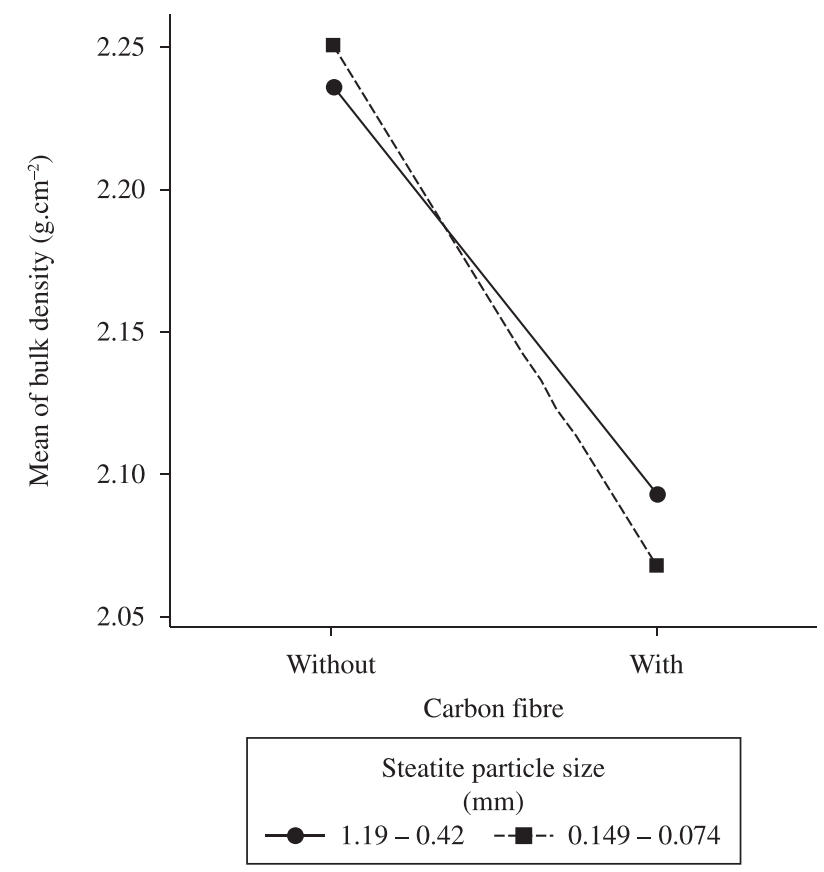

Figure 5. Interaction effect of steatite particle size and carbon fibre addition on the bulk density of the composites.

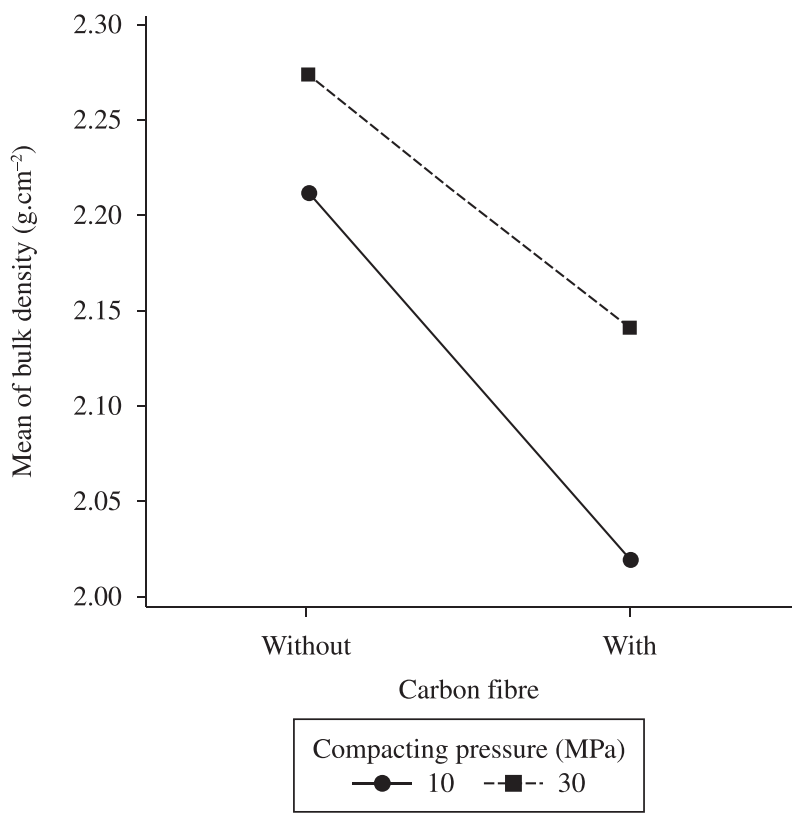

Figure 6. Interaction effect of compacting pressure and carbon fibre addition on the bulk density of the composites.

steatite fraction on the bulk density. It was observed that the addition of the steatite particles provided a maximum of the bulk density when $20 \%$ steatite was added. Apparently there is a trade off between two effects, on the one hand the addition of higher density steatite particles leads to an increase of the overall density of the composite, while on the hand steric hinderance effects by the carbon fibres and steatite particles reduces the density of the composite. Thus, not only the individual physical properties of the phases, but also particle packing significantly affect the response.

This behaviour is further evidenced by the interaction effect plot of the steatite particle size and carbon fibre addition $\left(\mathrm{P}^{*} \mathrm{~A}\right)$ on bulk density (Figure 5). The carbon fibre addition provided a reduction of the bulk density of the composites, which is attributed to the lower density of the carbon fibres in regard of the matrix phase, but mainly to steric hinderance effects which result in a lower density of the composite.

Figure 6 shows the interaction effect plot of compacting pressure and carbon fibre addition $\left(\mathrm{P}^{*} \mathrm{~A}\right)$ for the bulk density. The increase 


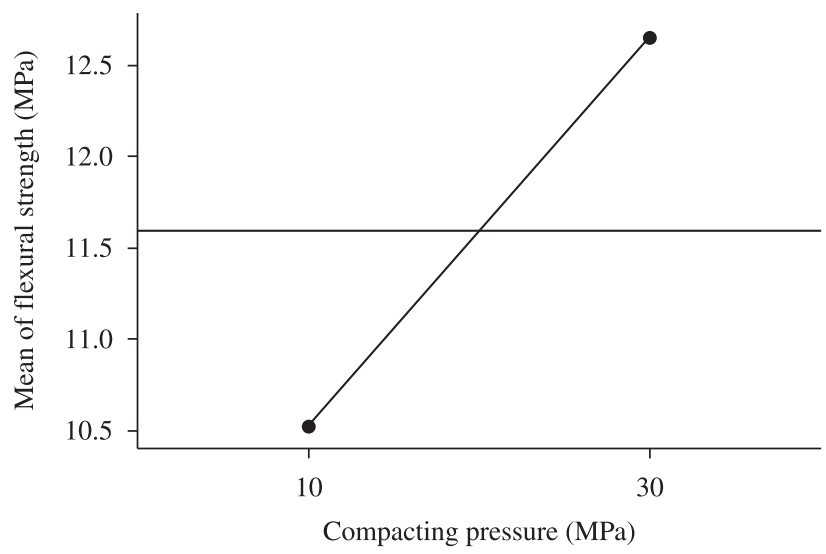

Figure 7. Main effect of compacting pressure on the flexural strength of the composites.

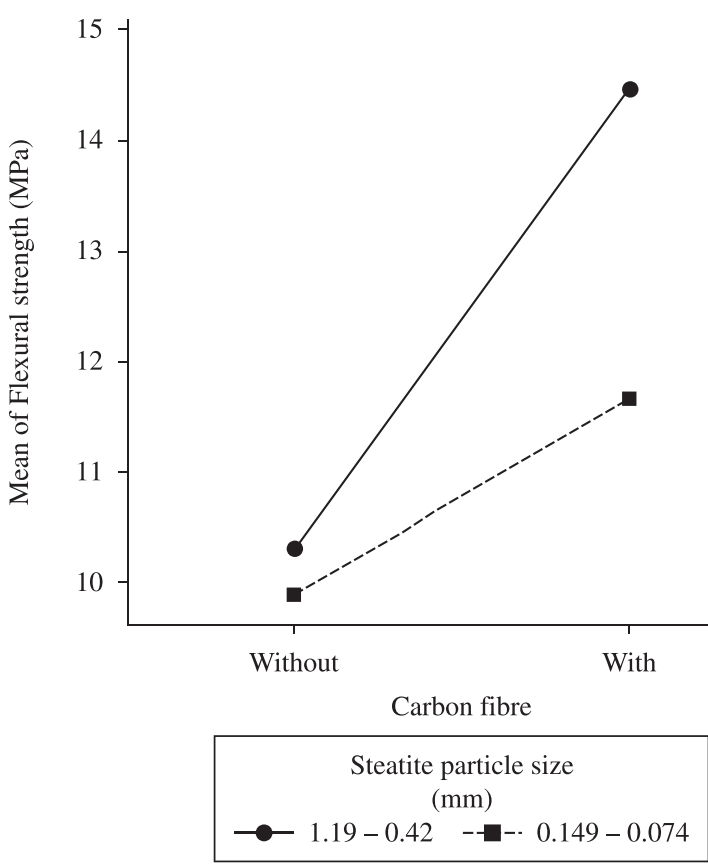

Figure 8. Interaction effect of steatite particle size and carbon fibre addition on the flexural strength of the composites.

of the compacting pressure from 10 to $30 \mathrm{MPa}$ provided an average percentage increase of $5.90 \%$ on the bulk density data. The reduction in bulk density provided by the carbon fibre addition was more evident when the low level of pressure (10 MPa) was employed.

\subsection{Flexural strength}

The flexural strength data varied from 8.02 to $18.22 \mathrm{MPa}$. The main factor compacting pressure $(\mathrm{P})$ and the interaction factors steatite particle size and carbon fibre addition $\left(\mathrm{P}^{*} \mathrm{~A}\right)$ were significant exhibiting a P-value lesser than 0.05 (Table 4). Figure 7 shows the effect of the compacting pressure $(\mathrm{P})$ on the flexural strength, revealing that the increase of the compacting pressure provides an increase of the flexural strength. A percentage variation of $19.86 \%$ was identified between the compacting pressure levels. According to Panzera et al. ${ }^{11}$ the increase of the compaction pressure provides high strength composites due to reduction of the porosity.

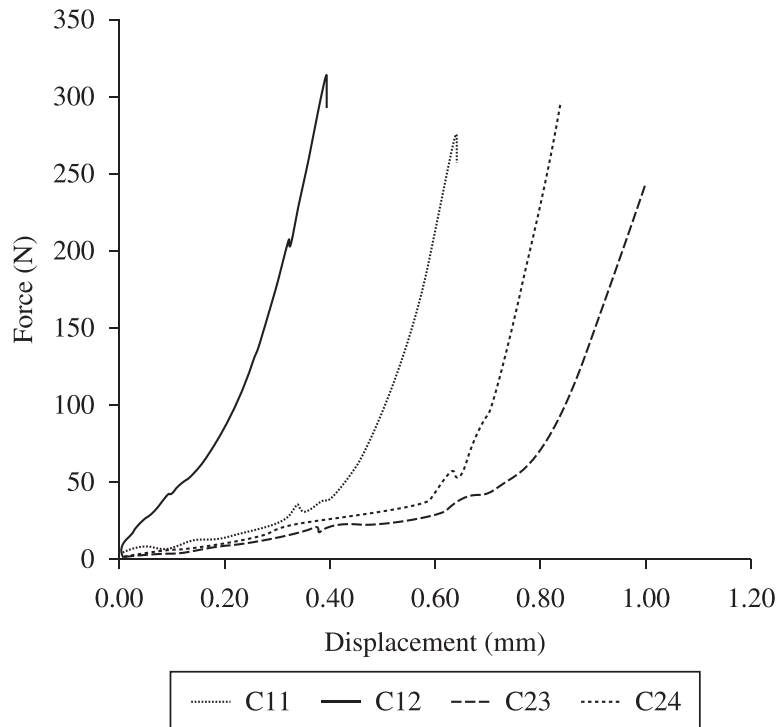

Figure 9. Mechanical behaviour of composites in flexural testing.

The interaction effect plot of compacting pressure and carbon fibre addition $\left(\mathrm{P}^{*} \mathrm{~A}\right)$ is presented in Figure 8. The flexural strength of the composites increased when the composites are manufactured with coarse particles of steatite $(1.19-0.42 \mathrm{~mm})$ and carbon fibre addition. The steatite particle size of 1.19-0.42 mm exhibits a smaller surface area in comparison to the fine particles $(0.148-0.074 \mathrm{~mm})$, enhancing the particle packing of the system. For this reason, the presence of pores is reduced and the mechanical strength is increased.

Figure 9 exhibits the mechanical behaviour in flexure of composites $\mathrm{C} 11, \mathrm{C} 12, \mathrm{C} 23$ and $\mathrm{C} 24$ which were manufactured with $30 \mathrm{MPa}$ of pressure and $40 \%$ of steatite particle fraction. Composites $\mathrm{C} 12$ and C24 were reinforced with parallel carbon fibres. It was verified an increase of stiffness and strength as a function of the carbon fibre addition. The composites manufactured with steatite particle size range of $0.149-0.074 \mathrm{~mm}(\mathrm{C} 23$ and $\mathrm{C} 24)$ presented a superior toughness compared to composites $\mathrm{C} 11$ and $\mathrm{C} 12$ which were manufactured with larger steatite particle size (1.19-0.42 mm).

Finally, the addition of carbon fibres not only decreased the bulk density, but also increased the mechanical strength of the cementitious composites, which is satisfactory for restoration application. An ongoing investigation evaluates the apparent porosity, shear strength and the surface adhesion between the composite and the soapstone.

\section{Conclusion}

The bulk density and the flexural strength of compacted cementitious composites with steatite waste and carbon fibre additions were investigated. The effect of the factors: steatite particle size and fraction, compacting pressure and carbon fibre addition were analyzed using the Design of Experiment (DOE) methodology. It was concluded that the experimental condition $\mathrm{C} 12$ which was manufactured with $40 \%$ of steatite particles $(1.19-0.42 \mathrm{~mm}), 30 \mathrm{MPa}$ of compaction and carbon fibre addition exhibited suitable properties for restoration and maintenance of carved soapstone elements. The carbon fibre addition increased the flexural strength of the composites, which allows higher steatite waste content in the mixes as well as the development of a special mortar with similar texture and colour of the natural stone.

\section{Acknowledgements}

The financial support of FAPEMIG is gratefully acknowledged. 


\section{References}

1. Mielcarek W, Wozny DN and Prociow K. Correlation between $\mathrm{MgSiO}$ phases and mechanical durability of steatite. Journal of the European Ceramic Society. 2004. 24: 3817-3821.

2. White JS. Particle-size distribution of steatite talc. Journal of the American Ceramic Society. 1994; 27: 320-323.

3. Silva ME and Roeser HMP. Mapeamento de deteriorações em monumentos históricos de pedra-sabão em ouro preto. Revista Brasileira Geografia. 2003; 33: 331-338.

4. Takarli M, Phelipot-Mardele A and Prince W. Adaptation of the MicroDeval Test for Assessing the Surface Weathering Degree of Granite. Journal of ASTM International. 2009; 6: 1-11.

5. Strecker K, Panzera TH, Sabariz ALR and Miranda JS. The effect of incorporation of steatite wastes on the mechanical properties of cementitious composites. Material \& Structure. 2010; 43: 923-932.
6. Associação Brasileira de Normas Técnicas. NBR 11578: Cimento Portland Composto. Rio de Janeiro; 1991.

7. Werkema MCC and Aguiar S. Planejamento e análise de experimentos: como identificar e avaliar as principais variáveis influentes em um processo. Belo Horizonte: FCO; 1996.

8. Montgomery DC. Introduction to statistical quality control. USA: John Wiley \& Sons; 1997.

9. British Standard. BS EN 658-3. Advanced technical ceramics. Mechanical properties of ceramic composites at room temperature. Determination of flexural strength; 2002.

10. British Standard. BS EN 12390-2. Testing hardened concrete. Making and curing specimens for strength tests; 2000.

11. Panzera TH, Rubio JC, Bowen CR and Walker PJ. Microstructural design of materials for aerostatic bearings. Cement \& Concrete Composites. 2008; 30: 649-660. 